\title{
Miscellany
}

\section{United Kingdom Central Council for Nursing, Midwifery and Health Visiting}

The College receives regular communications from the UKCC concerning professional conduct and changes to the Council's Register. If Members of the College would like further information, they should contact the UKCC at the following address: Registration Confirmations, UKCC, 23 Portland Place, London WIN 4JT. Direct telephone line: 01716313200 (8 am-6 pm).

\section{Design a logo for a new College campaign}

A small working party, chaired by Professor Arthur Crisp, has been meeting to draft a proposal for a new College campaign entitled Every Family in the Land. We are eager to ensure that any new College stigma campaign has its own identity and the working party is keen to involve the College at large in the quest for a suitable logo. If you are an artist or just a doodler and interested in this challenge, we would like to hear from you. Finished artwork is not required as the winning design will be developed by a designer. The reward will be the satisfaction of seeing your logo on the campaign stationery for a period of five years. Please send your designs to Deborah Hart of the External Affairs Department at the College.

\section{New publications}

\section{AIDS Reference Manual}

For those giving support to people with HIV and AIDS and their families, the AIDS Reference Manual is now available for $£ 39.50$ (inc. P \& P) from NAM (National AIDS Manual) Publications, 16a Clapham Common Southside, London SW4 $7 \mathrm{AB}$.

Transforming Health in London, the King's Fund London Commission Report published in July of this year recommends sweeping changes to improve health services for people of London. This is now available for $\$ 25$ from the King's Fund book shop on 01713072591.

A new journal entitled Current Awareness in Forensic Mental Health has recently been launched to provide a source of information on reports, books and journal articles published in the fleld of forensic mental health, listed by subject. The introductory subscription price for six issues a year is £75. Orders and further information: Library and Information Service, Rampton Hospital Authority, Retford, Nottingham DN22 OPD.

Physical Signs of Sexual Abuse in Children (2nd edn) is a new working party report of the Royal College of Physicians. It is hoped that this information will help children and families by offering guidance to those who have responsibility in contributing to diagnoses and decisionmaking in this area. Further information: The Royal College of Physicians, 11 St Andrews Place, Regent's Park, London NW1 4LE (Telephone: 0171935 1174).

The Health and Safety Executive (HSE) has issued a free leaflet entitled The Management of Health and Safety at Work Regulations 1992 Updated to include changes affecting young people and new and expectant mothers. The leaflet helps employers, employees and representatives to understand the amended regulations by bringing together the full, updated text and explaining the changes which have been made. Further information: HSE Information Centre, Broad Lane, Sheffield S3 7HQ (InfoLine: $0541545500)$.

\section{College Bye-Laws and Regulations}

The revised Bye-Laws and Regulations of the College are now available, free of charge, to all Members of the College. Copies can be obtained from the Books Sales Office on extension 146. 